\title{
Medical treatment of rare diseases must be put on the agenda
}

This article was published in the following Dove Press journal:

Orphan Drugs: Research and Reviews

22 September 2011

Number of times this article has been viewed

\section{Lise Aagaard}

Faculty of Pharmaceutical Sciences, University of Copenhagen, University of Copenhagen, Copenhagen, Denmark
Correspondence: Lise Aagaard Department of Pharmacology and Pharmacotherapy, Section for Social Pharmacy, Universitetsparken 2, 2100

Copenhagen, Denmark

Email laa@farma.ku.dk
The development of medicines for the treatment of rare diseases is important to many, including both patients and prescribers, but has traditionally been of minor interest to the pharmaceutical industry due to the often low number of patients with a rare disease. Politicians and regulators have recently acknowledged this problem, and favorable licensing conditions are now offered to pharmaceutical companies developing new medications for rare diseases to make these products more accessible.

In the USA, the Rare Diseases Act was approved in 2002, and this legislation amended the Public Health Service Act to establish the Office of Rare Diseases Research. It also increased funding for the development of treatments for patients with rare diseases. The European Union (EU) has enacted similar legislation, Regulation (EC) No 141/2000, in which pharmaceuticals developed to treat rare diseases are referred to as "orphan medicinal products." The EU's definition of an orphan condition is broader than that of the USA, in that it also covers some tropical diseases that are primarily found in developing nations. Orphan drug status granted by the European Commission gives marketing exclusivity in the EU for 10 years after approval. The EU's legislation is administered by the Committee for Orphan Medicinal Products of the European Medicines Agency.

In an effort to reduce the burden on manufacturers applying for orphan drug status, the US Food and Drug Administration and European Medicines Agency agreed in late 2007 to utilize a common application process for both agencies. However, the two agencies will continue to maintain separate approval processes. In addition to the USA and the EU's legislation, Japan, Singapore, and Australia have all passed legislation that offers subsidies and other incentives to encourage the development of drugs that treat orphan diseases.

In many countries, national committees are being established to focus attention on the topic at national level and patient organizations are also involved in ensuring the topic is on the political agenda. Over the last decade, 62 pharmaceutical products have been licensed for use, 35 of which were for the treatment of rare cancer diseases.

Orphan drugs generally follow the same regulatory development path as other pharmaceutical products, in which testing focuses on pharmacokinetics and pharmacodynamics, dosing, stability, safety, and efficacy. However, some statistical burdens are lessened to maintain development momentum. For example, orphan drug regulations generally acknowledge that it may not be possible to test 1000 patients in a 
Phase III clinical trial, as fewer than that number may be afflicted with the disease in question.

Since the market for any drug with such a limited application scope would, by definition, be small and thus largely unprofitable, government intervention is often required to motivate a manufacturer to address the need for an orphan drug. Critics of free market enterprise often cite this as a failure of free market economic systems.

The launch of the new peer-reviewed open-access journal Orphan Drugs: Research and Reviews is timely and important as it will focus attention on further research in this area, and it is hoped that the articles published therein will be of importance to medical professionals as well as contribute to the public debate.

Orphan Drugs: Research and Reviews welcomes submissions on all areas of the design and development of orphan drugs to clinical application, evaluation of clinical outcomes, and programs for the development and effective, safe, and sustained use of medicines. A number of highly qualified editorial board members have been recruited and selected and, with the administrative and technical support from the publisher Dove Medical Press, it is hoped that the journal will be able to publish a large number of interesting papers in the near future.

\section{Publish your work in this journal}

Orphan Drugs: Research and Reviews is an international, peer-reviewed, open access journal publishing original research, reports, reviews and commentaries on all areas of the design and development of orphan drugs for the treatment of rare diseases through to clinical applications. Clinical outcomes, patient safety, and programs for the development and effective, safe, and sustained use of medicines will be a feature of the journal. The manuscript management system is completely online and includes a very quick and fair peer-review system, which is all easy to use. Visit http://www.dovepress.com/testimonials.php to read real quotes from published authors. 